\title{
Graphene Encapsulated Ni@N/C Catalyst for Highly Selec- tive Semi-hydrogenation of Terminal Alkynes
}

\author{
Jianguo Liu ${ }^{\text {a, b, d* }}$, Jiangmin Sun ${ }^{\mathrm{c}, \mathrm{d}}$, Shanshan Lin ${ }^{\mathrm{d}, \mathrm{e}}$, Longlong Ma ${ }^{\mathrm{a}, \mathrm{d} *}$ \\ a Key Laboratory of Energy Thermal Conversion and Control of Ministry of Education, School of Energy and Environment, \\ Southeast University, Nanjing 210096, PR China. \\ ${ }^{\mathrm{b}}$ Dalian National Laboratory for Clean Energy, Chinese Academy of Sciences, Dalian 116023, P. R. China. \\ ${ }^{c}$ School of Energy Science and Engineering, University of Science and Technology of China, Hefei 230026, P. R. China. \\ ${ }^{\mathrm{d}}$ Guangzhou Institute of Energy Conversion, Chinese Academy of Sciences, Guangzhou 510640, P. R. China. \\ ${ }^{\mathrm{e}}$ University of Chinese Academy of Sciences, Beijing 100049, P. R. China. \\ * Corresponding author: liujg@ms.giec.ac.cn; mall@ms.giec.ac.cn
}

KEYWORDS: Graphene $・$ nitrogen doping・Ni@N/C・semi-hydrogenation・terminal alkynes

\begin{abstract}
Although precious transition metals such as palladium, platinum, and iridium have been widely used in hydrogenation reactions, the earth-abundant transition metal-catalyzed highly selective semi-hydrogenation of alkynes, especially terminal alkynes to terminal alkenes remains challenging and poor developed. We demonstrate herein that excellent selective, costeffective semi-hydrogenation of terminal alkynes can be realized via novel none precious graphene encapsulated Ni@ N/C catalyst. The precise regulation of the graphene layer for the encapsulated nano-catalyst Ni@N/C can avoid metal leaching and increase catalytic stability significantly. Nitrogen has strong interaction with Ni nanoparticles, which regulate the activity of Ni towards selective semi-hydrogenation of terminal alkynes. The substrate having un-functionalized as well as functionalized substituents, challenging hydrogenation sensitive functional groups (olefins, ketones), were semi-hydrogenated with excellent conversion (up to $99 \%$ ) and selectivity (up to $99 \%$ ).
\end{abstract}

Semi-hydrogenation of alkynes to alkenes represents an important transformation in organic synthesis and has been widely used in the fine chemical industry and petroleum industry. ${ }^{1-5}$ It is well known that alkyne could be hydrogenated to alkene easily using transition metal catalyst $(\mathrm{Pd}, \mathrm{Pt}, \mathrm{Rh}, \mathrm{Ru}$, Ir), but normally with undesired over reduction product alkane..$^{6-9}$ In the olefin industry, the alkene is the crucial substarting marital for the synthesis of various valuable products like rubbers and plastics. ${ }^{10-12}$ However, during the selective hydrogenation of alkyne to an alkene, starting material alkyne and the over-reduction product alkane are the impurity and harmful components which poisoned the subsequent alkene polymerization process. So, the developments of controllable excellent selective hydrogenation of alkyne to the alkene, which can lower alkyne concentration and increase desired alkene product, are of great importance. ${ }^{13-16}$

a) Representative noble metal-based heterogeneous catalysts
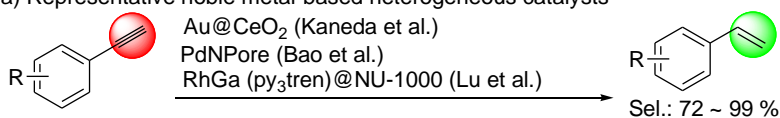

b) Representative non-noble metal-based heterogeneous catalysts

NiZn $/$ AlSBA-15 (L.Yang et al.) $\mathrm{NiZn}_{3} /$ AISBA-15 (L.Yang et al.)
Ni-fructose@SiO -800 (K.Murugesan et al.) NiCu Nanoalloy (H.Konnerth et al.)

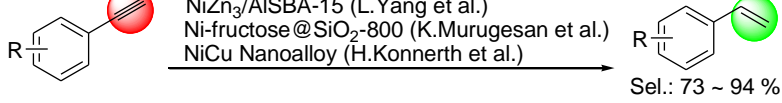

c) $\mathrm{N}$-doped thin graphene layer encapsulated $\mathrm{Ni}$ catalyst<smiles>c1ccc(-c2ccccc2)cc1</smiles>

$\mathrm{Ni@N/C}$

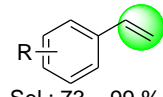

Scheme 1. Heterogeneous transition metal-catalyzed Semihydrogenation of Terminal Alkynes

Up to now, a variety of high efficient transition metal catalysts have been developed and applied in the semi-hydrogenation of alkyne to the alkene, and some of them have been widely applied in industry. Precious transition metals like Pd, $\mathrm{Rh}$, Ir, Au were widely used in the semi-hydrogenation of internal alkynes, which normally favored Z-selectivity. Recently, many Pd, $\mathrm{Au}$, and Ru catalyzed selective semi-hydrogenation of terminal alkyne, which has been recognized as more challenging substrates than internal alkyne in semi-hydrogenation, have been developed and showed good to excellent catalytic activity and selectivity. ${ }^{3,14,17-20}$ Kaneda and coworkers made a great contribution to the Core-Au/Shell$\mathrm{CeO}_{2}$ catalyst for the semi-hydrogenation of alkynes. ${ }^{21}$ They prepared the novel core-shell nanocomposite Au@ $\mathrm{CeO}_{2}$ catalyst using a facile synthesis redox co-precipitation method through the spontaneous redox reaction between $\mathrm{Au}(\mathrm{III})$ with $\mathrm{Ce}$ (III) to $\mathrm{Au}(0)$ and $\mathrm{Ce}$ (IV). The core-shell structure was important for the catalytic activity and stability, it can minimize the exposed surface Au sites and maximize the coreshell interfacial sites. Under mild reaction conditions (Au@ $\mathrm{CeO}_{2}$ (Au: 10 mol\%), r.t., 30-50 atm $\mathrm{H}_{2}$ ), various alkynes including aromatic, aliphatic terminal alkynes, and internal alkynes were transformed to alkene product with good to excellent selectivity (72 >99\%) (Scheme 1a). In 2017, Bao and co-workers ${ }^{22}$ reported a heterogeneous palla$\operatorname{dium}(\mathrm{Pd}(0)$ NPore $)$ catalyst for semi-hydrogenation of terminal alkynes. Ten terminal alkynes including aromatic and aliphatic substrates were converted to the desired terminal alkenes in 75 88\% yield under mild conditions ( $1 \mathrm{~atm}$ of $\mathrm{H}_{2}$, rt). One equiv. $\mathrm{NaOH}$ and 16-20 h reaction time were necessary in all the cases (Scheme 1a). Recently, Lu et al. ${ }^{14}$ reported a novel system containing both active metal $\mathrm{Rh}(0)$ and promoter ion Ga (III) on metal-organic framework (MOF) support. The promoter Ga (III) could dramatically affect the 
semi-hydrogenation selectivity of the Rh-Ga@NU-1000 catalyst via the electronic (decreasing Rh electron density and making it more electropositive) and structural effect (limiting number of available coordination sites at $\mathrm{Rh}$ ). Unlike the previous report, the Rh-Ga@NU-1000 catalyst favored high selectivity of E-alkenes from internal alkynes, and also could selective semi-hydrogenated more than 10 examples of terminal alkynes to alkenes with $80 \sim 89 \%$ yield (Scheme 1a). Compared with the abovementioned precious transition metal catalysts, earth-abundant transition metal catalysts like $\mathrm{Fe}$, $\mathrm{Co}, \mathrm{Ni}$ (Scheme 1b) also showed promising application in the semi-hydrogenation of alkynes, especially with their obvious advantage in economic cost and bio-safety requirements. ${ }^{15,16,18,23-29}$ However, when concerning the most costeffective and promising heterogeneous supported earth-abundant transition metal catalysts, the unstable and gradually weaken metal-support interaction causing active metal species aggregation during reactions are generally one of the most factors which restrict their wide application in industry. Moreover, the supported metal-based catalysts also suffer from active species leaching in acids or other harsh reaction conditions, results in poor reactivity and selectivity in challenging synthetic organic reactions or poor stability. To solve these problems, recently, the core-shell, yolk-shell structure catalysts that encapsulate active metal nanoparticles (core) with support (shell) maintaining the high activity and stability of metals in the acidic medium are proved to be novel and promising and has recently been applied in a variety of catalytic systems. ${ }^{30-36}$ Graphene has been widely used as catalyst support due to its unique properties of thinnest, hardest, thermal and electrical conductivity. But the previous prepared graphene encapsulated catalysts generally have multi-layer of graphitic shell which reduced the catalytic reactivity, hence searching and developing advanced synthesis methods for thin graphene layers especially for twisted bilayer, three-layer graphene with superconductivity are of great interest. ${ }^{37-40}$

Herein, we report a facile and environmentally friendly synthesis of thin graphene shell encapsulated nitrogen doping $\mathbf{N i @ N / C ~ c a t a l y s t ~ u s i n g ~ n i c k e l ~ n i t r a t e ~ a n d ~ m e l a m i n e . ~ T h e ~ c a t - ~}$ alyst's chemical composition, morphology, phase structure, and its catalytic semi-hydrogenation of terminal alkynes are studied in detail.

The Ni@N/C catalysts were prepared using our previous report with some modification. ${ }^{41}$ Briefly, $\mathrm{Ni}$ nitrates, citric acid, and different amine sources were mixed in $\mathrm{EtOH}$ under vigorous stirring. Then the formed greenish gel was dried and calcined, yielding N-doped graphene encapsulated Ni@N/C catalysts (Scheme S1). As shown in Figure 1 of the representative scanning electron microscopy (SEM) images and transmission electron microscope (TEM) images, different amine sources affected the catalyst's surface significantly. The Ni@N/C-5 catalyst prepared from urea had a denser structure, while the other three catalysts $\mathbf{N i @ N / C - 1 , ~ N i @ N / C - 4 , ~}$ $\mathbf{N i @ N / C - 6 ~ p r e p a r e d ~ f r o m ~ m e l a m i n e , ~ a m m o n i u m ~ c i t r a t e , ~} 1,2$ propylene diamine respectively had looser structure, also have the obvious pore structures, this could be further confirmed by the BET measurements of the catalysts. As shown in Figure 1e- 1h, the nitrogen source can affect the metal nanoparticles' size dramatically. The Ni@N/C-1 has the uniform size of the metal species with $12.5 \mathrm{~nm}$, while the Ni@N/C-4 prepared with ammonium citrate has the smallest particle size $5.9 \mathrm{~nm}$. The Ni@N/C5 has an uneven metal nanoparticle size, and some of the metal species could be seen aggregation. The Ni@N/C-6 prepared with the aliphatic amine 1,2 propylene diamine has a very irregular metal particle size distribution. The further zoom of the selected area of Ni@N/C catalyst could see the formation of a thin gra- phene layer structure around the Ni. The catalyst prepared by using melamine has an obvious thin-layer graphene structure, and the graphene wraps the active $\mathrm{Ni}$ metal with about 5 numbers of carbon layers. While the catalysts Ni@N/C-4 and Ni@N/C-5 prepared by using ammonium citrate or urea as the nitrogen source have fewer carbon layers, and the structure of the carbon layers is incomplete, and some carbon layers are destroyed. For the catalyst prepared with 1,2 propanediamine, no obvious carbon-coated metal structure was observed, but the presence of a graphene carbon layer was observed. In addition, the TEM-EDS analysis and high-angle annular dark-field EDS (HAADF-EDS) elemental mapping of Ni@N/C-1 exhibited a very similar distribution, which further indicated the co-existence of both $\mathrm{N}$ and $\mathrm{Ni}$ species in the Ni@N/C-1 catalyst. The elements of C, N, and O were well dispersed over the $\mathrm{Ni}$ nanoparticles according to the elemental mapping of the Ni@N/C-1 catalyst, indicating the presence of graphene layers around the nanoparticles. The $\mathrm{C}, \mathrm{O}$, $\mathrm{N}$, and $\mathrm{Ni}$ atoms were also distributed homogeneously over the other prepared Ni@C catalysts (Figure S1).

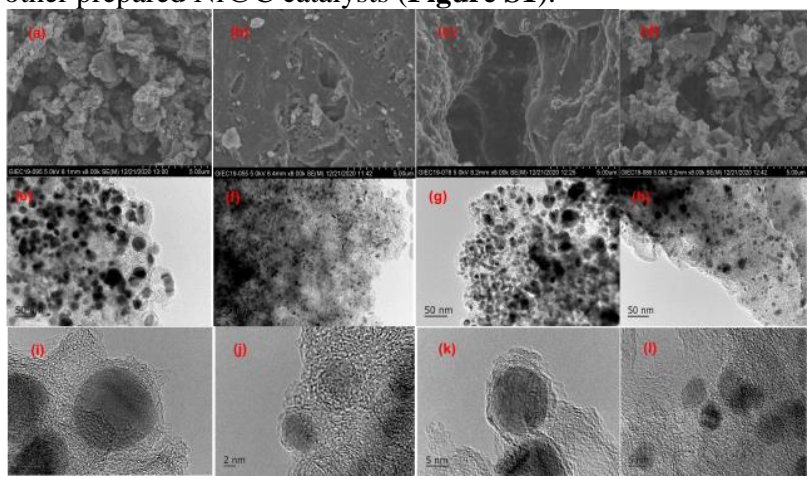

Figure 1. Representative SEM images of Ni@N/C-1 (a), Ni@N/C-4 (b) Ni@N/C-5 (c), Ni@N/C-6 (d); Representative HAADF-TEM images of $\mathrm{Ni} @ \mathrm{~N} / \mathrm{C}-1(\mathrm{e}, \mathbf{i}), \mathrm{Ni} @ \mathrm{~N} / \mathrm{C}-4(\mathbf{f}, \mathrm{j}), \mathrm{Ni} @ \mathrm{~N} / \mathrm{C}-5(\mathrm{~g}, \mathrm{k}), \mathrm{Ni} @ \mathrm{~N} / \mathrm{C}-6(\mathrm{~h}, \mathrm{l})$.

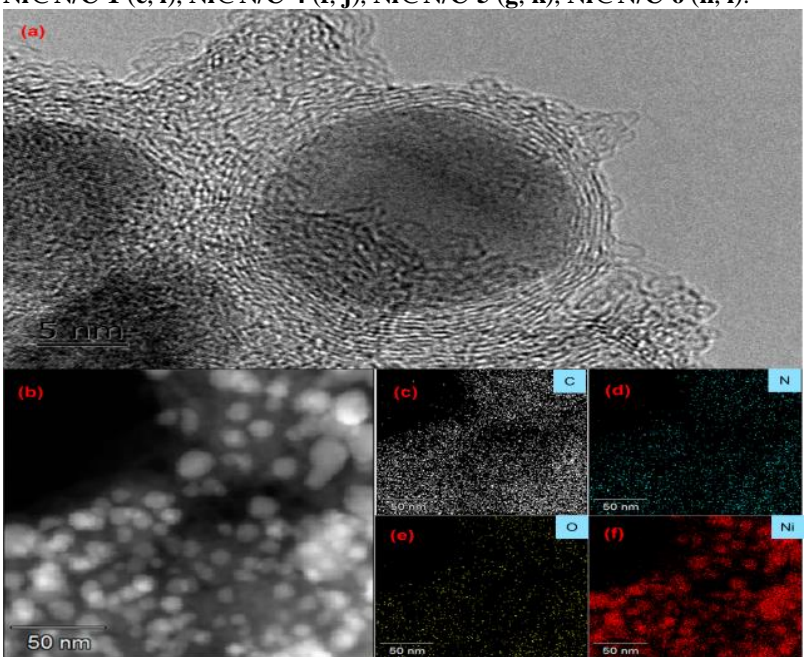

Figure 2. Representative HAADF-TEM images of Ni@N/C-1 (a) and corresponding EDS element mapping (EFTEM) of gray, C, N, O, and Ni (b-f). As shown in the PXRD profile of different catalysts (Figure 3a), the Ni@N/C-1 has the highest intensity which showed clearly the Ni (111), Ni (200), Ni (220) metal species. Also, the graphene shell $\mathrm{C}(002)$ can be observed, which agrees with the TEM analysis. The intensity of the $\mathrm{Ni}$ (111), Ni (200), $\mathrm{Ni}$ (220) metal species peaks is lower in the catalysts $\mathbf{N i @ N / C - 4 ~ a n d ~ N i @ N / C - 6 , ~ w h i c h ~ i n d i c a t e d ~ t h a t ~ t h e ~ m e t a l ~}$ species were dispersed well in the support. While here, it also needs to mention, the nitrogen sources have a great effect on the metal dispersion in the graphene support. The catalyst Ni@N/C-4 which was prepared from ammonium citrate has a higher loading of Ni metal, according to the ICP and SEMEDS analysis (Table S1, S2), but it has better dispersion than 
the Ni@N/C-1 catalyst prepared from melamine. For the catalyst Ni@N/C-6, which was prepared from the aliphatic amine 1,2 propylenediamine, it had the lowest Ni loading only $8.36 \%$ (Table S2), and also the Ni metal species with smaller nanoparticle size and better dispersion in the support, which following the TEM analysis. The X-ray photoelectron spectroscopy (XPS) was carried out to elucidate the chemical states of the Ni metal elements (Figure 3b-3e). The survey scan of all the catalysts $(\mathbf{N i} @ \mathbf{N} / \mathbf{C}-\mathbf{1}, \mathbf{4}, \mathbf{5 , 6})$ showed the presence of $\mathrm{Ni}, \mathrm{C}, \mathrm{O}$, and $\mathrm{N}$ elements. The catalyst Ni@N/C-1 and $\mathbf{N i @ N / C - 6 ~ h a d ~ a ~ s i m i l a r ~ f i g u r e ~ t r e n d ~ w i t h ~ t h e ~ p r e s e n c e ~}$ of metallic $\mathrm{Ni}^{0}$ peaks at BE $852.2 \mathrm{Ev}$ or $852.3 \mathrm{Ev}\left(\mathrm{Ni} 2 \mathrm{p}_{3 / 2}\right)$ after deconvolution. This was lower binding energy than the reported $\mathrm{Ni} / \mathrm{AC}$ and the even $\mathrm{N}$ doped $\mathrm{Ni} / \mathrm{AC}-\mathrm{N}-0.5$ catalysts, which indicated that the stronger electron density of the $\mathrm{Ni}$ atom in Ni@N/C-1 increased dramatically for the reported two catalysts. ${ }^{42-44}$ While the other two Ni@N/C-4 and $\mathbf{N i @ N / C - 5 ~ h a d ~ a ~ s i m i l a r ~ f i g u r e ~ t r e n d ~ w i t h ~ t h e ~ p r e s e n c e ~ o f ~}$ metallic $\mathrm{Ni}^{0}$ peaks at $\mathrm{BE} 852.3 \mathrm{eV}\left(\mathrm{Ni} 2 \mathrm{p}_{3 / 2}\right)$ after deconvolution. Moreover, the presence of a large quantity of high oxidation state of $\mathrm{Ni}^{2+}$ (II) species was also evident by the peaks at $\mathrm{BE}$ 854.3-854.5 eV $\left(\mathrm{Ni} 2 \mathrm{p}_{3 / 2}\right), \mathrm{BE}$ 856.6-857.7 eV $\left(\mathrm{Ni} 2 \mathrm{p}_{1 / 2}\right)$ and $\mathrm{BE} 871.3-872.1 \mathrm{eV}\left(\mathrm{Ni} 2 \mathrm{p}_{3 / 2}\right)$. All of these observations indicated that the active metal species $\mathrm{Ni}^{0}$ were easily oxidized to $\mathrm{Ni}^{2+}$ (II) during the preparation. Furthermore, the N1s spectrum of $\mathbf{N i @ N / C - x}$ was recorded between 395.0 $\mathrm{eV}$ and $410.0 \mathrm{Ev}$. Deconvolution of the N1s spectra of $\mathbf{N i @ N / C - 1 ~ c a n ~ b e ~ f i t t e d ~ i n t o ~ t h r e e ~ p e a k s ~ o f ~ n i t r o g e n ~ s p e c i e s ~}$ which were assigned to pyridinic-N, pyrrolic-N, graphitic-N respectively. ${ }^{28,42,44-46}$ It is proved that when the $\mathrm{N}$ content in the support increased, a charge transfer from $\mathrm{N}$ to $\mathrm{Ni}$ became more intense. As shown in the TEM-EDS element, when the nitrogen source changed from urea, ammonium citrate, and melamine, the content of $\mathrm{N}$ in the catalyst $\mathbf{N i @ N / C - 5 , ~}$ Ni@N/C-4, Ni@N/C-1 increased from 1.09\%, 1.56\% to 2.93\% gradually. The stronger interaction between the N-doped support and nickel, which comes from the enhanced electron transfer, could improve the stability and activity of the catalyst. As we all know, when the electron acceptor of pyridinic$\mathrm{N}$ species interacts with metal atoms, we can observe the positive binding energy shift. But for when the graphitic-N species donates electrons to the neighboring metal atoms, instead, we can obtain the negative binding energy shift. And this incensement of electron density could increase the Ni catalyst's selectivity. ${ }^{43,47}$ Furthermore, The $\mathrm{C} 1 \mathrm{~s}$ electrons were deconvoluted into the main four peaks centered at BE 284.2, 285.7, $286.8,288.3 \mathrm{eV}$, which can be assigned to graphitic carbon $\mathrm{C}-\mathrm{C} \mathrm{sp}{ }^{2}, \mathrm{C}-\mathrm{C} \mathrm{sp} /-\mathrm{C}-\mathrm{N}, \mathrm{C}-\mathrm{O}$, and $\mathrm{C}=\mathrm{O}$ type of carbons respectively. ${ }^{28,48,49}$ To know the surface physical properties of the catalysts, we carried out the nitrogen adsorption isotherms of series Ni@N/C catalysts' samples. As illustrated in Figure 3f-3i, all the nitrogen-doped Ni@N/C catalysts showed the typical type IV reversible adsorption isotherm curve, which indicates the existence of mesoporous. The Brunauer-Emmett-Teller surface area of Ni@N/C-1, Ni@N/C-4, $\mathbf{N i @ N / C - 5}$, and Ni@N/C-6 was calculated to be 297.6, 435.4, 200.7 , and $591.9 \mathrm{~m}^{2 *} \mathrm{~g}^{-1}$ respectively (Table $\mathbf{S 3}$ ). The nitrogen sources affected the catalysts' BET surface area significantly. The catalyst Ni@N/C-5 prepared from urea has the smallest surface area of $200.1 \mathrm{~m}^{2 *} \mathrm{~g}^{-1}$, with the largest pore diameter of $6.03 \mathrm{~nm}$. While for the catalyst Ni@N/C-6 prepared from aliphatic amine 1,2 propylenediamine, it had the largest BET surface area of $591.9 \mathrm{~m}^{2 *} \mathrm{~g}^{-1}$ and the smallest av- erage pore diameter of $3.24 \mathrm{~nm}$. Although the Ni@N/C-4 catalyst had a higher loading of Ni (32.1\%) than the Ni@N/C-1 catalyst (Ni loading 25.0\%), due to its smaller Ni particles and well dispersion in the support, it had a higher BET surface area of $435.4 \mathrm{~m}^{2 *} \mathrm{~g}^{-1}$ than Ni@N/C-1 catalyst $\left(297.6 \mathrm{~m}^{2 *} \mathrm{~g}^{-1}\right)$. According to the quenched solid density functional theory (QSDFT) model, the pore-size distribution of these Ni@N/C-1 samples reveals main peaks in the range of approximately $3 \mathrm{~nm}$ to $5 \mathrm{~nm}$. Based on all these characterization results, the following views can be obtained: the most active catalyst, Ni@N/C-1, is characterized by the formation of specific metallic Ni nanoparticles, which are encapsulated in a thin graphene shell.

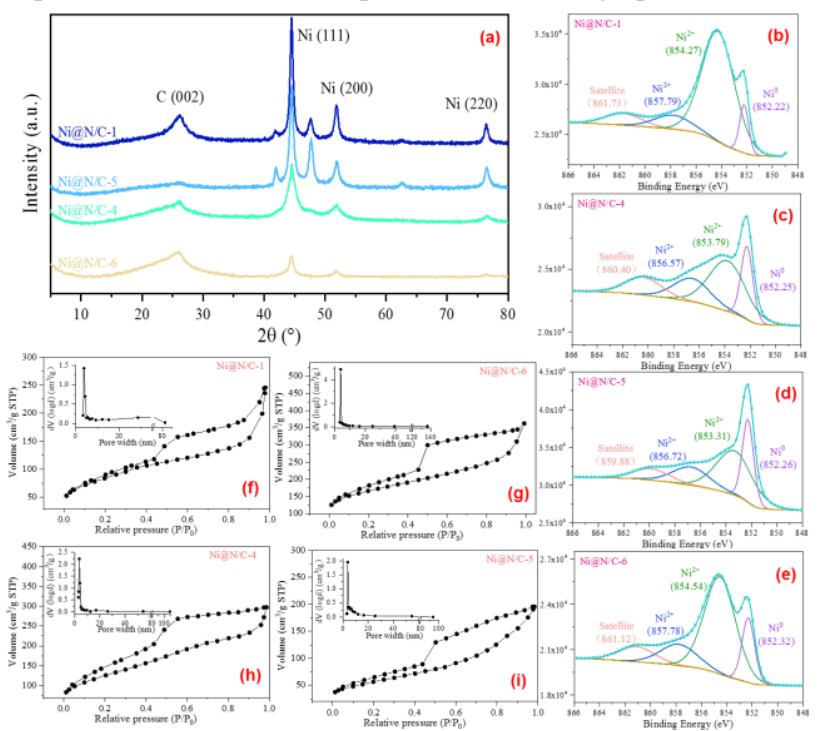

Figure 3. Representative XRD images of Ni@N/C-1, Ni@N/C-4, Ni@N/C5 , Ni@N/C-6 (a); representative XPS images of Ni@N/C-1 (b), Ni@N/C-4 (c), Ni@N/C-5 (d), Ni@N/C-6 (e); representative BET measurements of $\mathrm{N}_{2}$ adsorption and desorption isotherm curves and pore size distribution profile of catalysts Ni@N/C-1 (f), Ni@N/C-4 (h), Ni@N/C-5 (g), Ni@N/C-6 (i).

With the successful development of graphene thin layer encapsulated N-doped catalysts (Ni@N/C-x), we were interested in their general application for the semi-hydrogenation of challenging terminal alkynes substrates. Herein, we choose the hydrogenation of phenylacetylene as the standard reaction for the catalysts' activity and reaction conditions' evaluations. As shown in Figure 4a, all the prepared N-doped catalysts were evaluated in the standard reaction conditions. It is clear to see that they gave different catalytic reactivity and product selectivity for the hydrogenation of phenylacetylene. The Ni@N/C-1 gave the best results among the catalysts with 53\% of conversion and $94 \%$ of 1a selectivity, and the other overhydrogenated product selectivity of 6\%. The Ni@N/C-4 and Ni@N/C-6 were not active for the semi-hydrogenation of phenylacetylene under the selected reaction conditions. With the optimized catalyst Ni@N/C-1 in hand, we next evaluated the reaction temperature. As illustrated in Figure 4b, the conversion increased from $79 \%$ to $99 \%$ when the reaction temperature increased from $70{ }^{\circ} \mathrm{C}$ to $100{ }^{\circ} \mathrm{C}$, while in the meantime, the 1a selectivity showed a decreasing trend accordingly. At $80{ }^{\circ} \mathrm{C}$, the Ni@N/C-1 catalyzed semi-hydrogenation of phenylacetylene gave the best results of $92 \%$ conversion and $87 \%$ of 1 a selectivity. Then under this reaction temperature, we shorten and prolonged the reaction time to see the catalytic activity and product distributions. As shown in Figure 4c, when the reaction time was prolonged from $6 \mathrm{~h}$ to $9 \mathrm{~h}$, the conversion increased from $86 \%$ to $99 \%$, but the product selectivity decreased from $85 \%$ to $50 \%$. Although the cyclohexane and $\mathrm{CH}_{3} \mathrm{CN}$ gave excellent selectivity, the catalyst showed low activity in these solvents. 


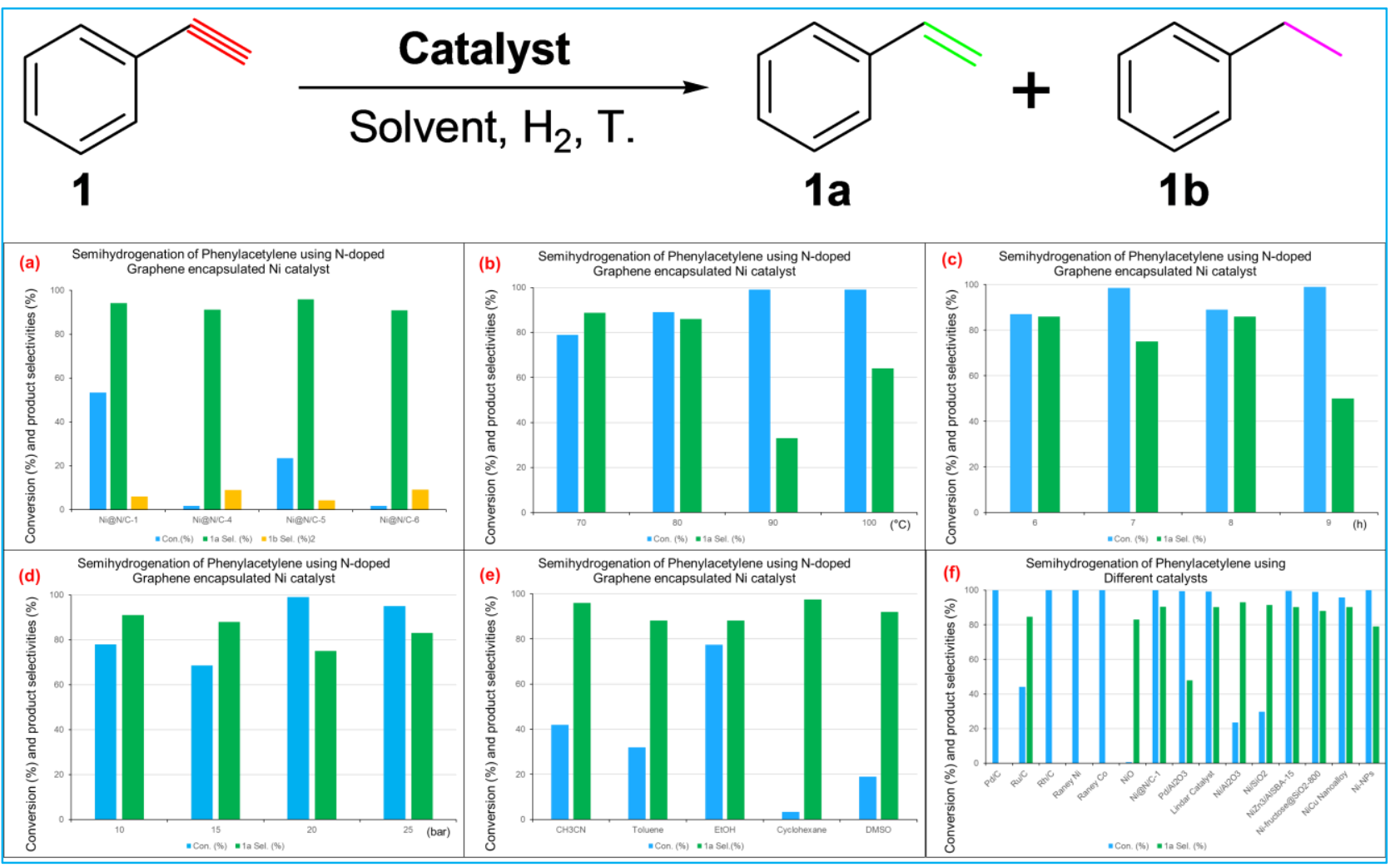

Figure 4. Optimization of semi-hydrogenation of Phenylacetylene using N-doped Graphene encapsulated Ni catalyst and comparaion with other catalysts. (a) Reaction conditions: $0.5 \mathrm{mmol}$ Phenylacetylene, $5 \mathrm{mg}$ catalyst, $4 \mathrm{ml}$ of $\mathrm{MeOH}, 20$ bar $\mathrm{H}_{2}$, r.t. 20 h.; (b) Reaction conditions: $0.5 \mathrm{mmol}$ Phenylacetylene, $5 \mathrm{mg}$ catalyst, $4 \mathrm{ml}$ of $\mathrm{MeOH}, 20$ bar $\mathrm{H}_{2}, 70-100{ }^{\circ} \mathrm{C}, 8 \mathrm{~h}$.; (c) Reaction conditions: $0.5 \mathrm{mmol}$ Phenylacetylene, $5 \mathrm{mg}$ catalyst, $4 \mathrm{ml}$ of MeOH, 20 bar $\mathrm{H}_{2}$, $80{ }^{\circ} \mathrm{C}$, 6-9 h.; (d) Reaction conditions: 0.5 mmol Phenylacetylene, $5 \mathrm{mg}$ catalyst, $4 \mathrm{ml}$ of MeOH, 10-25 bar $\mathrm{H}_{2}, 80{ }^{\circ} \mathrm{C}, 7 \mathrm{~h}$.; (e) Reaction conditions: 0.5 mmol Phenylacetylene, $5 \mathrm{mg}$ catalyst, $4 \mathrm{ml}$ of solvent, 20 bar $\mathrm{H}_{2}, 80^{\circ} \mathrm{C}, 7 \mathrm{~h}$.; (f) Reaction conditions: Pd/C, Ru/C, Rh/C, Raney Ni, Raney Co, NiO (0.5 mmol Phenylacetylene, $5 \mathrm{mg}$ catalyst, $4 \mathrm{ml}$ of $\mathrm{MeOH}, 20$ bar $\left.\mathrm{H}_{2}, 80{ }^{\circ} \mathrm{C}, 7 \mathrm{~h}\right)$; $\mathbf{N i} @ \mathbf{N} / \mathbf{C}-1$ ( 10 bar $\left.\mathrm{H}_{2}, 70{ }^{\circ} \mathrm{C}, 8 \mathrm{~h}\right) ; \mathbf{P d} / \mathbf{A l}_{2} \mathbf{O}_{3}(5 \mathrm{wt} \%$ phenylacetylene in $\mathrm{MeOH}, 1$ bar $\mathrm{H}_{2}, 40{ }^{\circ} \mathrm{C}, 1.3 \mathrm{~h}$ ); Lindlar catalyst $\left(5 \mathrm{wt} \%\right.$ phenylacetylene in $\mathrm{MeOH}, 1$ bar $\left.\mathrm{H}_{2}, 40{ }^{\circ} \mathrm{C}, 30 \mathrm{~h}\right)$; $\mathbf{N i} / \mathbf{A l}_{2} \mathbf{O}_{\mathbf{3}}(5 \mathrm{wt} \%$ phenylacetylene in MeOH, 10 wt $\%$ Ni loading, 1 bar $\mathrm{H}_{2}, 40{ }^{\circ} \mathrm{C}, 15 \mathrm{~h}$ ); Ni/SiO 2 (5 wt $\%$ phenylacetylene in $\mathrm{MeOH}, 10 \mathrm{wt} \% \mathrm{Ni} \mathrm{loading}, 1$ bar $\mathrm{H}_{2}, 40{ }^{\circ} \mathrm{C}, 15 \mathrm{~h}$ ); $\mathbf{N i Z n} 3 / \mathbf{A l S B A}-$ 15 (40) (5 wt\% phenylacetylene in $\mathrm{MeOH}, 1$ bar $\mathrm{H}_{2}, 40^{\circ} \mathrm{C}, 15.5 \mathrm{~h}$ ); Ni-fructose@SiO $\mathbf{2}_{\mathbf{2}}-\mathbf{8 0 0}$ (1 mmol phenylacetylene, $8 \mathrm{mg}$ catalyst (0.6 mol\% Ni), 2 Ml $\mathrm{CH}_{3} \mathrm{CN}, 10$ bar $\left.\mathrm{H}_{2}, 110^{\circ} \mathrm{C}, 5 \mathrm{~h}\right)$; NiCu Nanoalloy (0.005 mol, $50 \mathrm{mg}$ pre-NiCu/MMO, isopropanol, 4 bar $\left.\mathrm{H}_{2}, 100{ }^{\circ} \mathrm{C}, 3 \mathrm{~h}\right)$; Ni-NPs $(0.38 \mathrm{mmol}$ Phenylacetylene, $10.5 \mathrm{mg}\left[\mathrm{Ni}(\mathrm{COD})_{2}\right]$ in $0.15 \mathrm{~g}$ ionic liquid $\left[\mathrm{CNC}_{3} \mathrm{MMM} \mathrm{NTf}_{2}\right.$ prepared in situ, $0.5 \mathrm{~mL}$ cyclohexane, 4 bar $\mathrm{H}_{2}, 30{ }^{\circ} \mathrm{C}, 3 \mathrm{~h}$ ); $\mathrm{The}$ conversion and selectivity were determined by GC or NMR analysis using internal standard or reported in the literature.

Furthermore, to showcase the generality and selectivity of this novel $\mathrm{N}$-doped graphene layer encapsulated $\mathrm{Ni}$-based nano-catalyst, its reactivity was compared with other commercially available catalysts, the Lindlar catalyst, and some representative recently reported catalysts ${ }^{27,50-52}$. As illustrated in Figure 4f, the commercially noble catalysts $\mathbf{P d} / \mathbf{C}, \mathbf{R h} / \mathbf{C}$, Raney Ni, and Raney Co, which were usually used as hydrogenation catalysts due to their excellent hydrogenation ability, gave the full conversion of the semi-hydrogenation of phenylacetylene but with the over-hydrogenated alkane product. The less active Ru/C catalyst gave $40 \%$ conversion and $85 \%$ 1a selectivity. The $\mathbf{N i O}$ was not active for the phenylacetylene semi-hydrogenation during the selected reaction condition. With a slight modification of reaction conditions (10 bar $\mathrm{H}_{2}, 70{ }^{\circ} \mathrm{C}, 8 \mathrm{~h}$ ), the $\mathbf{N i @ N / C - 1 ~ e x h i b i t e d ~ e x c e l l e n t ~ r e a c t i v i t y ~}$ of $99 \%$ conversion and comparable excellent selectivity of 91\%. The prepared $\mathbf{P d} / \mathbf{A l}_{2} \mathbf{O}_{3}$ had excellent activity but with a low selectivity (47.8\%) under mild reaction conditions (1 bar $\mathrm{H}_{2}, 40{ }^{\circ} \mathrm{C}, 1.3 \mathrm{~h}$ ). Although the commercially widely used catalyst Lindlar catalyst shows a high selectivity $(90.2 \%)$ and super activity ( $99 \%$ con.), the reaction needs a long reaction time of up to 30 hours. Although the other two Ni-based catalysts $\mathbf{N i} / \mathrm{Al}_{2} \mathrm{O}_{3}$ and $\mathbf{N i} / \mathrm{SiO}_{2}$ showed excellent selectivity (93\% and $92 \%$ ) under 1 bar of $\mathrm{H}_{2}$ pressure and mild reaction temperature of $40{ }^{\circ} \mathrm{C}$, they had lower activity, with conversions of only $23.5 \%$ and $29.8 \%$, respectively, even prolonging the reaction time of up to 15 hours. The reported bi-metal NiZn3 /AISBA-15(40), and NiCu Nanoalloy catalysts gave the similar 1a selectivity of $90 \%$ with $99 \%$ and $96 \%$ conversion respectively at the modified reaction conditions separately. The in situ prepared Ni-NPs catalyst could also give super reactivity of $100 \%$ conversion and moderate $\mathbf{1 a}$ selectivity of $79 \%$ with the help of ionic liquid under mild reaction conditions. Under slightly harsh reaction conditions (10 bar $\mathrm{H}_{2}, 110{ }^{\circ} \mathrm{C}, 5 \mathrm{~h}$ ), the Ni-fructose@SiO2-800 catalyst can semi-hydrogenate phenylacetylene with $99 \%$ conversion and $88 \%$ 1a selectivity.

After having the optimized reaction conditions in hand, we then evaluated the substrate scope of Ni@N/C-1 catalyzed semi-hydrogenation reaction. As shown in Table 2, using the Ni@N/C-1 under the optimized reaction conditions of 20 bar $\mathrm{H}_{2}, 80{ }^{\circ} \mathrm{C}, 7 \mathrm{~h}$, most of the aromatic alkynes substrates could be transformed to the corresponding target alkene products with excellent conversion and selectivity (exceeds 99\%), which indicating that the graphene encapsulated Ni@N/C-1 catalyst's superior application in the field of non-noble heterogeneous catalyzed semi-hydrogenation reactions. The standard substrate phenylacetylene gave $99 \%$ conversion and $75 \%$ 1a product selectivity could be obtained under the given standard reaction condition. The $\mathbf{1 a}$ selectivity could be increased to $91 \%$ under slight modification of the reaction conditions. Then we first investigated the electronic effect of the substituent group on the meta position of aromatic alkynes. For substrate 2 with the electron-withdrawing group $-\mathrm{NH}_{2}$ on the meta position, full conversion of $>99 \%$ and $87 \%$ selectiv- 
ity were obtained. The substrate $\mathbf{3}$ bearing the strongest electron-withdrawing group -F at the meta position was a bit difficult to semi-hydrogenate and only gave $61 \%$ conversion and $86 \%$ 3a selectivity. While for the other two less electronwithdrawing groups - $\mathrm{Br}$ and $-\mathrm{Cl}$, no matter where the substituent group was located on the meta or ortho position, the catalyst showed excellent catalytic reactivity and product selectivity. We then further examined the effect of changing the substituent group at the para position of the aromatic alkynes. Interestingly, substrate 6 with the strongest electron-withdrawing group $\mathrm{NO}_{2}$ could produce the chemo semi-hydrogenation product $\mathbf{6 a}$ in excellent conversion and good selectivity. The substrate having the strong electron-donating group $\mathrm{NMe}_{2}$ also gave an excellent conversion of $94 \%$ and excellent selectivity of $99 \%$. The substrates with weak electron-donating group t-butyl, N-propyl, only gave moderated conversion but without any over-hydrogenation products. The graphene encapsulated Ni@N/C-1 also showed excellent catalytic reactivity of $93 \%$ conversion and $74 \%$ selectivity for the $E$ isomer product(12a). Here it is known that the electronwithdrawing and electron-donating groups can both delocalize the electron negativities of the aromatic ring, which can further affect the terminal alkynes' electron negativity. Here, the substrates have electron-withdrawing groups $\mathrm{NH}_{2}, \mathrm{Br}, \mathrm{Cl}$, $\mathrm{NO}_{2}, \mathrm{NMe}_{2}$ gave higher catalytic reactivity and selectivity of the desired semi-hydrogenated product than the substrates with electron-donating groups of t-butyl, N-propyl.

Table 2. Substrate Scope of Ni@N/C-1 catalyzed semi-hydrogenation of aromatic alkynes

(1)

${ }^{a}$ Reaction conditions: $0.5 \mathrm{mmol}$ Phenylacetylene, $5 \mathrm{mg}$ catalyst, $4 \mathrm{ml}$ of $\mathrm{MeOH}, 20$ bar $\mathrm{H}_{2}$, r.t. 20 h. ${ }^{\text {b }}$ Reaction conditions: $0.5 \mathrm{mmol}$ Phenylacetylene, $5 \mathrm{mg}$ catalyst, $4 \mathrm{ml}$ of $\mathrm{MeOH}, 20 \mathrm{bar}_{2}$, r.t. 20 h. The conversion and selectivity were determined by GC or NMR analysis using internal standard or reported in the literature.

The Ni@N/C-1 catalyst's stability and recycling test were further carried out in both batch reactor and advanced flow reactor. Surprisingly, the graphene encapsulated Ni@N/C-1 catalyzed semi-hydrogenation of phenylacetylene did not loss significant reactivity and product selectivity after 10 times' recycling test (Table S4). And also it needs to mention, the stable catalyst with magnetic properties can be applied in the industrially applicable flow reactor, and reaction conditions can be optimized easily by switching the control valve. The catalyst showed excellent reactivity and selectivity for the semi-hydrogenation of phenylacetylene in the flow reactor and the catalyst can be recovered easily (Table S5, Scheme S2). The graphene encapsulated Ni-based catalysts semi-hydrogenation in flow reactor process was high environmental friendlier with producing less byproduct and easily recycling use of $\mathrm{H}_{2}$. This can provide a feasible reference method for industrialized selective production of ethylene.

\section{CONCLUSIONS}

In summary, we have reported the successful facile synthesis of $\mathrm{N}$-doped thin graphene layer encapsulated Ni-based catalyst. The nitrogen sources had a great effect on the catalyst physical properties and interaction between support and active metal species, which further affected the Ni@N/C catalysts' activity and selectivity for semi-hydrogenation of aromatic alkynes. The optimized Ni@N/C catalyst showed excellent activity and selectivity for semi-hydrogenation of phenylacetylene under mild reaction conditions. More than 10 aromatic alkynes substrates could be transformed to the corresponding alkene product with good to excellent reactivity and selectivity. The graphene encapsulated $\mathrm{Ni@N/C} \mathrm{catalyst}$ also had good stability and can be applied in the industrially applicable flow reactor, which showed a promising method for ethylene synthesis in industry.

\section{ADDITIONAL INFORMATION}

Corresponding Author

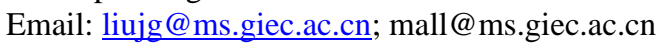

Author Contributions

J.-G. L. and L.-L.M. conceived and designed the experiments. J.-G. L., J. M. S. and S.S. L. performed experiments, data analysis and prepared the Supplementary Information. J.-G. L. wrote the paper. All authors discussed the results and commented on the manuscript.

\section{ACKNOWLEDGMENT}

This work was supported financially by the National Natural Science Foundation of China (Project 51976225), Dalian National Laboratory Cooperation Foundation, Chinese Academy of Sciences (Project DNL201916).

\section{REFERENCES}

[1] Prof. Dr. Johannes G. de Vries, P. D. C. J. E. The Handbook of Homogeneous Hydrogenation. (WILEY-VCH Verlag GmbH \& Co. KGaA, 2006).

[2] Crespo-Quesada, M., Cardenas-Lizana, F., Dessimoz, A. L. \& KiwiMinsker, L. Modern Trends in Catalyst and Process Design for Alkyne Hydrogenations. ACS Catal. 2, 1773-1786 (2012).

[3] Michaelides, I. N. \& Dixon, D. J. Catalytic Stereoselective Semihydrogenation of Alkynes to E-Alkenes. Angew. Chem. Int. Ed. 52, 806808 (2013).

[4] Oger, C., Balas, L., Durand, T. \& Galano, J. M. Are Alkyne Reductions Chemo-, Regio-, and Stereoselective Enough To Provide Pure (Z)-Olefins in Polyfunctionalized Bioactive Molecules? Chem. Rev. 113, 1313-1350 (2013). 
[5] Delgado, J. A., Benkirane, O., Claver, C., Curulla-Ferre, D. \& Godard, C. Advances in the preparation of highly selective nanocatalysts for the semihydrogenation of alkynes using colloidal approaches. Dalton Trans. 46, 12381-12403 (2017).

[6] Karunananda, M. K. \& Mankad, N. P. E-Selective Semi-Hydrogenation of Alkynes by Heterobimetallic Catalysis. J. Am. Chem. Soc. 137, 1459814601 (2015).

[7] Takale, B. S. et al. Unsupported Nanoporous Gold Catalyst for Chemoselective Hydrogenation Reactions under Low Pressure: Effect of Residual Silver on the Reaction. J. Am. Chem. Soc. 138, 10356-10364 (2016). [8] Vile, G., Albani, D., Almora-Barrios, N., Lopez, N. \& Perez-Ramirez, J. Advances in the Design of Nanostructured Catalysts for Selective Hydrogenation. Chemcatchem 8, 21-33 (2016).

[9] McCue, A. J., Guerrero-Ruiz, A., Ramirez-Barria, C., Rodriguez-Ramos, I. \& Anderson, J. A. Selective hydrogenation of mixed alkyne/alkene streams at elevated pressure over a palladium sulfide catalyst. J. Catal. 355, 40-52 (2017).

[10] Benavidez, A. D. et al. Improved selectivity of carbon-supported palladium catalysts for the hydrogenation of acetylene in excess ethylene. Appl. Catal., A 482, 108-115 (2014).

[11] Chesnokov, V. V., Podyacheva, O. Y. \& Richards, R. M. Influence of carbon nanomaterials on the properties of $\mathrm{Pd} / \mathrm{C}$ catalysts in selective hydrogenation of acetylene. Mater. Res. Bull. 88, 78-84 (2017).

[12] Choe, K. et al. Fast and Selective Semihydrogenation of Alkynes by Palladium Nanoparticles Sandwiched in Metal-Organic Frameworks. Angew. Chem. Int. Ed. 59, 3650-3657 (2020).

[13] Chernichenko, K. et al. A frustrated-Lewis-pair approach to catalytic reduction of alkynes to cis-alkenes. Nat. Chem. 5, 718-723 (2013).

[14] Desai, S. P. et al. Well-Defined Rhodium-Gallium Catalytic Sites in a Metal-Organic Framework: Promoter-Controlled Selectivity in Alkyne Semihydrogenation to E-Alkenes. J. Am. Chem. Soc.140, 15309-15318(2018). [15] Gorgas, N. et al. Efficient Z-Selective Semihydrogenation of Internal Alkynes Catalyzed by Cationic Iron (II) Hydride Complexes. J. Am. Chem. Soc. 141, 17452-17458 (2019).

[16] Ramirez, B. L. \& Lu, C. C. Rare-Earth Supported Nickel Catalysts for Alkyne Semihydrogenation: Chemo- and Regioselectivity Impacted by the Lewis Acidity and Size of the Support. J. Am. Chem. Soc. 142, 5396-5407 (2020).

[17] Fu, S. M. et al. Ligand-Controlled Cobalt-Catalyzed Transfer Hydrogenation of Alkynes: Stereodivergent Synthesis of Z- and E-Alkenes. J. Am. Chem. Soc. 138, 8588-8594 (2016).

[18] Tokmic, K. \& Fout, A. R. Alkyne Semihydrogenation with a WellDefined Nonclassical Co- $\mathrm{H}_{2}$ Catalyst: $\mathrm{A} \mathrm{H}_{2}$ Spin on Isomerization and ESelectivity. J. Am. Chem. Soc. 138, 13700-13705 (2016).

[19] Gramigna, K. M., Dickie, D. A., Foxman, B. M. \& Thomas, C. M. Cooperative $\mathrm{H}_{2}$ Activation across a Metal-Metal Multiple Bond and Hydrogenation Reactions Catalyzed by a $\mathrm{Zr} / \mathrm{Co}$ Heterobimetallic Complex. ACS Catal. 9, 3153-3164 (2019).

[20] Wang, Y. L., Huang, Z. D. \& Huang, Z. Catalyst as colour indicator for endpoint detection to enable selective alkyne trans-hydrogenation with ethanol. Nat Catal 2, 529-536 (2019).

[21] Mitsudome, T. et al. One-step Synthesis of Core-Gold/Shell-Ceria Nanomaterial and Its Catalysis for Highly Selective Semihydrogenation of Alkynes. J. Am. Chem. Soc. 137, 13452-13455 (2015).

[22] Lu, Y. et al. Highly Selective Semihydrogenation of Alkynes to Alkenes by Using an Unsupported Nanoporous Palladium Catalyst: No Leaching of Palladium into the Reaction Mixture. ACS Catal. 7, 8296-8303 (2017).

[23] Meng, X. C. et al. Selective hydrogenation of nitrobenzene to aniline in dense phase carbon dioxide over Ni/gamma- $\mathrm{Al}_{2} \mathrm{O}_{3}$ : Significance of molecular interactions. J. Catal. 264, 1-10 (2009).

[24] Polshettiwar, V., Baruwati, B. \& Varma, R. S. Nanoparticle-supported and magnetically recoverable nickel catalyst: a robust and economic hydrogenation and transfer hydrogenation protocol. Green Chem. 11, 127-131 (2009).

[25] Tanabe, K. K. et al. Discovery of Highly Selective Alkyne Semihydrogenation Catalysts Based on First-Row Transition-Metallated Porous Organic Polymers. Angew. Chem. Int.Ed. 53, 12055-12058 (2014). [26] Fedorov, A., Liu, H.-J., Lo, H.-K. \& Coperet, C. Silica-Supported Cu Nanoparticle Catalysts for Alkyne Semihydrogenation: Effect of Ligands on Rates and Selectivity. J. Am. Chem. Soc. 138, 16502-16507 (2016).

[27] Liu, Y. et al. Layered double hydroxide-derived $\mathrm{Ni}-\mathrm{Cu}$ nanoalloy catalysts for semi hydrogenation of alkynes: Improvement of selectivity and anti-coking ability via alloying of $\mathrm{Ni}$ and Cu. J. Catal. 359, 251-260 (2018). [28] Jaiswal, G. et al. N-Graphitic Modified Cobalt Nanoparticles Supported on Graphene for Tandem Dehydrogenation of Ammonia-Borane and Semihydrogenation of Alkynes. ACS Sustainable Chem. Eng. 8, 11058-11068 (2020).

[29] Shi, X. et al. Fabrication of Ni3N nanorods anchored on N-doped carbon for selective semi-hydrogenation of alkynes. J. Catal. 382, 22-30, (2020).

[30] Lee, I., Joo, J. B., Yin, Y. D. \& Zaera, F. A Yolk@Shell Nanoarchitecture for $\mathrm{Au} / \mathrm{TiO}_{2}$ Catalysts. Angew. Chem. Int. Ed. 50, 10208-10211 (2011).
[31] Holgado, J. P., Ternero, F., Gonzalez-delaCruz, V. M. \& Caballero, A. Promotional Effect of the Base Metal on Bimetallic $\mathrm{Au}-\mathrm{Ni} / \mathrm{CeO}_{2}$ Catalysts Prepared from Core-Shell Nanoparticles. ACS Catal. 3, 2169-2180 (2013).

[32] Li, Z. W., Mo, L. Y., Kathiraser, Y. \& Kawi, S. Yolk-Satellite-Shell Structured Ni-Yolk@Ni@SiO 2 Nanocomposite: Superb Catalyst toward Methane $\mathrm{CO}_{2}$ Reforming Reaction. ACS Catal. 4, 1526-1536 (2014).

[33] Movahed, S. K., Lehi, N. F. \& Dabiri, M. Palladium nanoparticles supported on core-shell and yolk-shell $\mathrm{Fe}_{3} \mathrm{O}_{4} @$ nitrogen doped carbon cubes as a highly efficient, magnetically separable catalyst for the reduction of nitroarenes and the oxidation of alcohols. J. Catal. 364, 69-79 (2018).

[34] Almeida, C. V. S., Tremiliosi, G., Eguiluz, K. I. B. \& Salazar-Banda, G. $\mathrm{R}$. Improved ethanol electro-oxidation at $\mathrm{Ni} @ \mathrm{Pd} / \mathrm{C}$ and $\mathrm{Ni} @ \mathrm{PdRh} / \mathrm{C}$ coreshell catalysts. J. Catal. 391, 175-189 (2020).

[35] Gao, J. et al. Ambient Hydrogenation and Deuteration of Alkenes Using a Nanostructured Ni-Core-Shell Catalyst. Angew. Chem. Int. Ed. (2021).

[36] Kim, S., Lauterbach, J. \& Sasmaz, E. Yolk-Shell Pt-NiCe@ $\mathrm{SiO}_{2}$ SingleAtom-Alloy Catalysts for Low-Temperature Dry Reforming of Methane. ACS Catal.11, 8247-8260 (2021).

[37] Geim, A. K. \& Novoselov, K. S. The rise of graphene. Nat. Mater. 6, 183-191 (2007)

[38] Castro Neto, A. H., Guinea, F., Peres, N. M. R., Novoselov, K. S. \& Geim, A. K. The electronic properties of graphene. Rev. Mod. Phys. 81, 109-162 (2009).

[39] Wong, D. L. et al. Cascade of electronic transitions in magic-angle twisted bilayer graphene. Nature 582, 198-202 (2020).

[40] Park, J. M., Cao, Y., Watanabe, K., Taniguchi, T. \& Jarillo-Herrero, P. Tunable strongly coupled superconductivity in magic-angle twisted trilayer graphene. Nature 590, 249-255 (2021).

[41] Liu, J. G. et al. Facile synthesis of controllable graphene-co-shelled reusable $\mathrm{Ni} / \mathrm{NiO}$ nanoparticles and their application in the synthesis of amines under mild conditions. Green Chem. 22, 7387-7397 (2020).

[42] Guimon, C., Auroux, A., Romero, E. \& Monzon, A. Acetylene hydrogenation over $\mathrm{Ni}-\mathrm{Si}-\mathrm{Al}$ mixed oxides prepared by sol-gel technique. Appl.Catal., A 251, 199-214 (2003).

[43] Wang, L., Li, F. X., Chen, Y. J. \& Chen, J. X. Selective hydrogenation of acetylene on $\mathrm{SiO}_{2}$-supported Ni-Ga alloy and intermetallic compound. $J$. Energy Chem. 29, 40-49 (2019).

[44] Xu, Z., Zhou, S. \& Zhu, M. Ni catalyst supported on nitrogen-doped activated carbon for selective hydrogenation of acetylene with high concentration. Catal. Commun. 149 (2021)

[45] Liang, H. W., Wei, W., Wu, Z. S., Feng, X. L. \& Mullen, K. Mesoporous Metal-Nitrogen-Doped Carbon Electrocatalysts for Highly Efficient Oxygen Reduction Reaction. J. Am. Chem. Soc. 135, 16002-16005 (2013).

[46] Xiong, W. et al. Nitrogen-doped carbon nanotubes as a highly active metal-free catalyst for nitrobenzene hydrogenation. Appl. Catal., B 260 (2020).

[47] Chen, Y. \& Chen, J. Selective hydrogenation of acetylene on $\mathrm{SiO}_{2}$ supported Ni-In bimetallic catalysts: Promotional effect of In. Appl. Surf. Sci. 387, 16-27 (2016).

[48] Liu, J. Y., Chang, H. Y., Truong, Q. D. \& Ling, Y. C. Synthesis of nitrogen-doped graphene by pyrolysis of ionic-liquid-functionalized graphene. J. Mater. Chem. C 1, 1713-1716 (2013).

[49] Greczynski, G. \& Hultman, L. Compromising Science by Ignorant Instrument Calibration-Need to Revisit Half a Century of Published XPS Data. Angew. Chem. Int. Ed. 59, 5002-5006 (2020).

[50] Konnerth, H. \& Prechtl, M. H. G. Selective partial hydrogenation of alkynes to (Z)-alkenes with ionic liquid-doped nickel nanocatalysts at near ambient conditions. Chem. Commun. 52, 9129-9132 (2016).

[51] Murugesan, K., Alshammari, A. S., Sohail, M., Beller, M. \& Jagadeesh, R. V. Monodisperse nickel-nanoparticles for stereo- and chemoselective hydrogenation of alkynes to alkenes. J. Catal. 370, 372-377 (2019).

[52] Yang, L. et al. Semihydrogenation of phenylacetylene over nonprecious Ni-based catalysts supported on AlSBA-15. J. Catal. 370, 310-320 (2019). 